\title{
Assessing dimensions of executive function in community-dwelling older adults with self-neglect
}

\author{
Sabrina Pickens ${ }^{1}$, Sharon K. Ostwald ${ }^{1}$, Kathleen Murphy Pace ${ }^{1}$, Pamela Diamond ${ }^{2}$, Jason \\ Burnett $^{3}$, Carmel B. Dyer ${ }^{3}$
}

1. University of Texas Health Science Center at Houston's School of Nursing, Houston, Texas, U.S.A. 2. University of Texas Health Science Center at Houston's School of Public Health, Houston, Texas, U.S.A. 3. University of Texas Health Science Center at Houston's School of Medicine, Houston, Texas, U.S.A.

Correspondence: Sabrina Pickens. Address: University of Texas Health Science Center at Houston's School of Nursing, Houston, Texas, U.S.A. Email: sabrina.I.pickens@uth.tmc.edu

Received: January 29, 2013

Accepted: September 26, 2013

Online Published: October 23, 2013

DOI : $10.5430 /$ cns.v2n1p17

URL: http://dx.doi.org/10.5430/cns.v2n1p17

\section{Abstract}

Purpose: Self-neglect (SN) is the inability to maintain self-care needs. It is thought that older adults who have impaired executive function (EF) develop the inability to self-care and to protect themselves. The specific aims were to determine the feasibility of using multiple EF measures and assess the different dimensions of EF with community-dwelling elders with SN.

Methods: In this cross-sectional study, 50 adults aged 65 and older were recruited from Adult Protective Services with confirmed SN. A research nurse administered the following measures: Delis-Kaplan Card Sort Test (D-KEFS), Executive Interview (EXIT 25), CLOX Drawing Test (CLOX I, II), Trails Making Test A and B (TMT A \& B) and the Mini-Mental State Examination (MMSE). Descriptive analyses and Pearson correlation coefficients were conducted on the different variables used in this study.

Results: Older adults with SN were more likely to fail the CLOX1 and D-KEFS, while passing the other cognitive measures. The low D-KEFS scores indicate difficulties in generating new concepts, inhibiting previous conceptual thoughts, or initiating novel ideas.

Conclusions: Results from this study provide support that individuals with SN will complete a battery of EF tests and that they exhibit the following impairments consistent with executive dysfunction: “concept generation”, “planning, inhibition”, and "spatial working memory”. Utilizing only one EF measure in individuals with intact cognition may result in unidentification of individuals with executive dysfunction, thus delaying necessary treatment. Future studies should attempt to determine different etiologies of executive dysfunction and determine if early treatment can prevent or reverse SN.

\section{Key Words}

Self-neglect, Executive dysfunction, Older adults, Community-dwelling 


\section{Introduction}

Self-neglect (SN) is a person's unwillingness or inability to maintain self-care needs, whether due to cognitive impairments or reduced capacity, and is the most common type of elder abuse reported to Adult Protective Services (APS). According to the Survey of State Adult Protective Services (2004), approximately 175,000 cases of self-neglect in persons 60 years of age and older were reported in 34 states in the United States. Of these, approximately 80,000 cases were substantiated by APS. In 19 states, self-neglect (37.2\%) was the most common allegation substantiated by APS, followed by caregiver neglect (20.4\%) and financial exploitation (14.7\%) ${ }^{[1,2]}$. However, SN is a global phenomenon. Reports of SN in the literature include Singapore ${ }^{[3]}$, Australia ${ }^{[4,5]}$, United Kingdom ${ }^{[6]}$, Ireland ${ }^{[7,8]}$, Finland, Greece, Romania ${ }^{[9]}$ and Canada ${ }^{[10]}$, to name a few.

The etiology of SN is unknown, however, it is postulated that these individuals develop executive dysfunction (ED) which is the inability to make or carry out plans, as well as the inability to make voluntary decisions, two components of decisional autonomy ${ }^{[11]}$. Characteristics of ED commonly seen in older adults with SN include the inability to complete complex cognitive tasks (i.e., managing finances, identifying dangerous situations), the inability to maintain adequate hygiene or self-administer medications ${ }^{[11-14]}$.

The Mini-Mental State Examination (MMSE) is widely used to screen for global cognition in older adults ${ }^{[15]}$. However, even with a normal MMSE score, ED can be present in highly educated individuals ${ }^{[12]}$. The Clock Drawing Test, a visuospatial task, has traditionally been used to assess executive function. However, a failing test score in subjects with frontal impairment requires other measures of EF since the frontal impairment hinders the visuospatial conceptualization basic to this test ${ }^{[16]}$. In a recent retrospective study of the 538 cases of adults ages 65 years and older with SN, 355 (70\%) subjects failed the 4-point clock drawing test (CDT), a type of measure to screen for $\mathrm{ED}^{[17]}$. These researchers developed the Consortium for Research of Elder Self-neglect in Texas (CREST) model of self-neglect at the Texas Elder Abuse and Mistreatment Institute, which theorizes that frontal cerebral cortex damage due to specific medical conditions (i.e. nutritional deficiencies, cerebrovascular disease, dementia, depression, hypertension) contribute to the development of ED. These medical conditions were present in the 538 individuals with SN. Based on this model, once ED is present, manifestations of SN appear in individuals with impaired basic and instrumental activities of daily living in the absence of adequate social support services.

Executive function has been positively correlated with an older adult's functional status ${ }^{[12,18]}$. Frontal system lesions and frontal system hyper- and hypo-metabolism both contribute to the onset of ED leading to impairments in decisional capacity ${ }^{[16,18]}$. Having decisional making capacity requires individuals to make and carry out decisions ${ }^{[11]}$, an ability often lacking in elders with SN, which may help to explain their inability to maintain self-care needs.

Compared to other geriatric syndromes, little primary data exists about SN since its introduction into the medical literature in the late 1960s. Cardinal features for SN include refusal of care; multiple, untreated medical conditions; impaired cognition; living in filthy environments; lack of or refusal of social support; and poor personal hygiene, to name a few ${ }^{[17,19-24]}$. Studies have shown the majority of individuals with SN have dementia and/or depression, both of which can cause $\mathrm{ED}^{[17,19-21]}$.

Individuals confirmed to have SN are five times more likely to die within one year of being reported to APS based on a recent, prospective, population-based study ${ }^{[25]}$. Commonly, individuals with SN refuse medical treatment, therefore placing them at a higher risk for medical decline and, unfortunately, death. This lack of self-care and ability to protect themselves may stem from the presence of ED.

Individuals with intact executive function (EF) are able to take simple ideas, movements, or actions and develop them into complex behaviors that are goal-directed ${ }^{[11]}$. Impairments in EF contribute to caregiver burden and institutionalization due to patient morbidity ${ }^{[12,13]}$. Royall \& colleagues assert that no one EF measure can serve as the gold standard in assessing 
EF since individuals may have difficulty to only some of the EF's subsets ${ }^{[16]}$. Based on factor analyses, Royall et al identified the following dimensions of EF: concept generation, inhibition, spatial and verbal working memory and planning ${ }^{[16]}$. The primary aim of this study was to determine the feasibility of administering measures, testing these dimensions of EF in older adults with APS substantiated SN. The secondary aim of this study was to identify which EF subsets were present in older adults with APS substantiated SN.

\section{Methods}

\subsection{Design}

The subjects were recruited as part of a double-blind, randomized control trial (parent study) which tested the feasibility of providing different doses of vitamin D to subjects who were vitamin D deficient and had APS substantiated SN. The current study was a cross-sectional study of subjects ages 65 years and older with APS substantiated SN who were enrolled in the parent study. Subject enrollment occurred between January 2010 and February 2011. Subjects were consecutively enrolled until 50 subjects who met eligibility criteria were recruited. Prior to enrollment, this study was approved by the Institutional Review Board at The University of Texas Health Science Center at Houston (UTHSC-H) in Houston, Texas.

\subsection{Study population}

The subjects were asked to participate after the following inclusion criteria were verified: (1) 65 years of age and older, (2) English speaking, (3) self-neglect, substantiated by an APS worker (4) signed release form for UTHSC-H researchers to contact them, (5) resident of Harris County, Texas, (6) and community-dwelling. Subjects were excluded if they met any of the following criteria: (1) pre-diagnosed with a terminal illness (e.g. cancer), (2) resided in a nursing home, (3) planned to move out of the catchment area during the proposed study period, (4) unable to provide informed consent and no legal guardian present, (5) non-English speaking and (6) referred to APS for other forms of abuse. For this study, APS workers referred eligible subjects whose case was previously closed by APS. In a closed case either the subjects refused APS intervention or the primary reason for the referral to APS was resolved. Eligible subjects were contacted by telephone to set up a home visit. Once at the home, the research nurse read the consent form in its entirety. Afterwards, subjects repeated back the purpose of the study, procedures to be carried out, the risk and benefits to participation and any alternatives to participation prior to signing the consent form. A copy of the consent form was given to each subject.

\subsection{Variables and instruments}

Demographic data including age, monthly income, race, level of education, marital status, living arrangement, the number and type of co-morbidities and last physician visit were also collected.

Mini-Mental State Examination (MMSE). The MMSE consists of two sections. The verbal section tests orientation, memory and attention. The second section tests the ability to name, follow written and verbal commands, write a spontaneous sentence and copy two intersecting polygons. The scores range from 0 to $30^{[15]}$. Scores less than 24 are indicative of cognitive impairment ${ }^{[26]}$.

The MMSE has been validated in 206 patients with dementia and psychiatric illnesses and in 63 subjects considered normal ${ }^{[15]}$. The mean and standard deviation scores for the different diagnostic categories were: $X=9.6+5.8$ for patients with dementia, $X=19.0+6.6$ for patients with dementia and cognitive impairment, $X=25.1+5.4$ for patients with depression and $\mathrm{X}=27.6+1.7$ for patients without any type of cognitive impairments. The MMSE was correlated with the Wechsler Adult Intelligence Scale's Verbal and Performance scores to determine concurrent validity. Pearson $r=0.776(p$ $<0.0001)$ when the MMSE was compared to the Verbal IQ and Pearson $r=0.660(p<0.001)$ when the MMSE was compared to the Performance IQ. There was no significant difference on retest reliability when the MMSE was 
administered 28 days apart among elderly depressed and demented patients (Wilcoxon $\mathrm{T}=27.7$, NS, Pearson $r=0.988, p$ $<0.0001)^{[15]}$.

Trails Making Test (TMT) A and B. The TMT is composed of two parts: A and B. Both parts are scored based on the amount of time to task completion. Part A is a measure of global cognition and consists of individuals connecting circles numbered 1-25 in ascending order. Scores for Part A are 29 - 90 seconds (average) with $>78$ seconds considered unable to complete in a timely manner ${ }^{[27]}$.

Part B is a measure of EF, specifically the EF dimensions of inhibition and spatial working memory ${ }^{[16]}$. It consists of subjects connecting circled numbers and letters in ascending order but the subject needs to alternate between numbers and letters (i.e., 1-A-2-B, etc.). For Part B, the average score is 75 - 180 seconds and scores $>273$ seconds are considered unable to complete in a timely manner ${ }^{[27]}$.

The TMT was initially developed as part of the Army Individual Test Battery and has a moderate internal consistency $(\text { Kuder-Richardson }(\text { KR-20 })=0.84)^{[28]}$. The TMT has been validated in 200 subjects with brain damage and 84 subjects without brain damage. For both parts, mean score differences between the 2 groups were statistically significant $(\mathrm{CR}=$ $16.20, p<.001$ ). Similarly, for part B both groups were statistically significant based on their mean score differences (CR $=13.99, p<.001)^{[28]}$.

The Executive Interview (EXIT 25). The EXIT Interview is a 25-item paper and pencil measure of executive function for the dimensions of concept generation, inhibition, verbal working memory and spatial working memory ${ }^{[16]}$. Specifically, the tool is designed to identify executive impairments, predict self-care, functional status and predict problematic behaviors in the presence of executive impairments. Each of the items is scored from 0 to 2 with $0=$ intact performance, 1 $=$ partial error, and $3=$ incorrect response or inability to perform the task. Overall scores range from 0 to 50 with higher scores reflecting executive impairment. Abnormal cut-off scores are greater than 15/16 ${ }^{[29]}$.

The EXIT has acceptable validity and reliability estimates. The inter-rater reliability was high (Pearson's $r=0.90$ ). The tool has been validated against several neuropsychological measures. The EXIT inversely correlated with the MMSE ( $r=$ -.85), but strongly correlated with the Trails Making Test ( $\mathrm{r}=.73$ for part A, $r=.64$ for part B) and the Serial Attention Test (time, $r=.82$; errors, $r=.83$ ). However, only a moderate correlation was found with the Wisconsin Card Sorting Test $(r=.52)^{[29]}$.

Delis-Kaplan Card Sort Test (D-KEFS). The D-KEFS is a card sorting task to measure problem solving in subjects with frontal lobe pathology. The D-KEFS measures the EF dimensions of concept generation, inhibition and planning ${ }^{[16]}$.

The test involves two card sorting tasks. Each card set contains 6 cards of different sizes, shapes, colors and words. In task 1 , the subject is asked to sort the cards into as many of the 8 possible combinations as they can. After each sort they are asked to provide a rationale for their choices. They can stop once they have exhausted their possible sets. In task 2, the research nurse sorts the cards into all 8 possible sets. After each set, she asks the subject to give the rationale for that sort. The first set of conditions tests spontaneous sorting and the second set of conditions tests sort recognition. All raw scores are scaled to a mean of 10 and standard deviation of 3 based on the following age ranges: 60-69, 70-79 and 80-89. Scores below a mean of 10 are consistent with ED. The technical manual contains detailed scoring information ${ }^{[30]}$.

The internal consistency was moderate to high among subjects aged 60 to 89 years of age (Spearman-Brown correction of the Pearson correlation, .77-.82) ${ }^{[30]}$. For the same sample, subjects, on average, improved their scores from test 1 time to test 2 time, $\mathrm{r} 12=.0 .62-0.73^{[30]}$. The D-KEFS has been validated in older adults with frontal lobe pathology and Korsakoff's syndrome when compared with adults without frontal lobe pathology. For the first sort adults with frontal pathology performed significantly worse than normal adults for spontaneous sorts, accuracy in rule naming, attempted perseverated sorts and perseverated rule names $(p<.01)$. Similar results were found for the second set: number of sorting 
rules correctly names $(p<.001)$ and number of perseverated rule names $(p<.01)$. For the final set, adults with frontal lobe pathology showed impairment in card sorting when cued abstractly $(p<.001)$ or given explicit cues $(p<.02)^{[31]}$.

CLOX Drawing Test (CLOX). The CLOX is a two part test to measure executive function. CLOX I is a more direct measure of EF, specifically the EF dimensions of concept generation and spatial working memory ${ }^{[16]}$. Part one consists of instructing the subject to draw a clock and insert the time of 1:45 using hands and numbers in a clock. CLOX II is a more direct measure of global cognition. The second part consists of the administrator drawing the same clock and then having the subject copy the clock. Both parts are individually scored based on the completeness of drawing each of the clocks. Both scores range from 0 to 15 . A score of 10 or below on CLOX I and a score of 12 or below on CLOX II indicates executive impairment ${ }^{[32]}$.

The CLOX has high inter-rater reliability estimates (CLOX I, Pearson's $\mathrm{r}=0.94$, CLOX II, Pearson's $r=0.93$; both $p<$ 0.001) ${ }^{[32]}$. The CLOX also has a high internal consistency (Cronbach's alpha $=0.82$ ). After adjusting for age and education level, the EXIT 25 and MMSE strongly predicted CLOX I scores $\left[\mathrm{F}(4,82)=50.7, p<0.001 ; \mathrm{R}^{2}=0.71\right]$. However, the MMSE was the only measure which significantly contributed to scores on CLOX II $[\mathrm{F}(4,72)=57.2, p<$ $0.001, \mathrm{R} 2=0.74]^{[32]}$.

\subsection{Data collection procedure}

The following battery of tests was administered to all subjects by an experienced research nurse: EXIT 25 Interview (EXIT), Trails Making Test Parts A \& B (TMT A and B), Delis-Kaplan Card Sort Test (D-KEFS), and the CLOX Drawing Test. These EF measures assess the following dimensions of EF: concept generation, inhibition, spatial working memory, verbal working memory and planning.

The MMSE and a demographic collection form were also administered. The research nurse was trained on administering and scoring the instruments and provided return demonstrations after the training to verify the instruments were correctly administered. The assessments were conducted in the subject's home and took approximately an hour to complete.

\section{Results}

\subsection{Recruitment}

A total of 136 people with an APS-confirmed diagnosis of SN whose cases had been closed by APS were referred to the research team for possible enrollment. The research nurse was able to contact 125 subjects ( $92 \%$ of referrals). Of those subjects 45 (35\%) did not meet the study criteria. Of the remaining 80 subjects, 50 (62.5\%) were recruited into the study and $30(37.5 \%)$ refused participation. The number of subjects who completed each measure ranged from 36-48 (MMSE=48; CLOX I=46; CLOX II=44; D-KEFS Card Sort Test = 36, TMT A = 42; TMT B = 39; EXIT = 46). The missing items were due to subject fatigue or refusal to complete all measures.

The data were analyzed using the Statistical Package for the Social Sciences (SPSS) version $19.0{ }^{[33]}$. Descriptive analyses were conducted to determine the mean, median, range, mode and standard deviations for each measure. Means and standard deviations were calculated for age, income and educational level and frequencies were generated for race, gender, marital status, living situation, co-morbid conditions and last physician visit. Pearson correlation coefficients were calculated to assess relationships between age and highest level of education and the scores for each dependent measure. A one-way between-group analysis of variance (ANOVA) was conducted to determine if race had an impact on any of the measures. All D-KEFS' scores were converted to scaled scores based on age. 


\subsection{Demographics}

The demographic information is displayed in Table 1.

Table 1. Demographic characteristics for community-dwelling elders with adult protective services validated self-neglect $(\mathrm{N}=50)$

\begin{tabular}{|c|c|}
\hline Variable & Mean \pm SD \\
\hline Age in years & $75.70 \pm 7.14$ \\
\hline Income per year & $1120.11 \pm 600.19$ USD \\
\hline Education in years & $10.58 \pm 2.89$ \\
\hline Variable & N (\%) \\
\hline \multicolumn{2}{|l|}{ Race } \\
\hline African American & $23(46)$ \\
\hline White & $19(38)$ \\
\hline Hispanic American & $7(14)$ \\
\hline Asian & $1(2)$ \\
\hline \multicolumn{2}{|l|}{ Gender } \\
\hline Female & $29(58)$ \\
\hline Male & $21(42)$ \\
\hline \multicolumn{2}{|l|}{ Marital status } \\
\hline Married & $16(26.7)$ \\
\hline Divorced/Separated & $12(20)$ \\
\hline Widowed & $21(35)$ \\
\hline Never Married & $1(1.7)$ \\
\hline Variable & N (\%) \\
\hline \multicolumn{2}{|l|}{ Living arrangement } \\
\hline Alone/Has Hired Caretaker & $24(48)$ \\
\hline With Family/Has Hired Caretaker & $16(32)$ \\
\hline With Spouse Only & $10(20)$ \\
\hline
\end{tabular}

The mean age was $75.70+7.14$ years. The majority were African-American $(46 \%)$ and female (58\%). Only five of the subjects had a hired caretaker. Subjects had a mean monthly income of $\$ 1,120.00+600.19$ USD, and an average educational level of $10.58+2.89$.

\subsection{Co-morbidities}

Thirty-nine (78\%) of the subjects had a visit to their primary care physician within 3 months prior to the assessment. Table 2 provides the types of co-morbid conditions present in this sample.

The majority of subjects $(56 \%, \mathrm{n}=28)$ had at least 3 to 5 co-morbid conditions with a sample average of $4.82+2.43$. Thirty percent $(n=15)$ of individuals with self-neglect had six or more co-morbidities. The most common co-morbid conditions were hypertension (66.7\%), diabetes mellitus (36.7), hyperlipidemia (33.3\%), osteoarthritis (30\%), poor vision (23.3\%) and cardiac conditions (20\%). 
Table 2. Medical conditions for community-dwelling elders with Adult Protective Services validated self-neglect in this study $(\mathrm{N}=50)$

\begin{tabular}{ll}
\hline Type of medical condition & N (\%) \\
\hline Hypertension & $40(66.7)$ \\
Diabetes Mellitus & $22(36.7)$ \\
Hyperlipidemia & $20(33.3)$ \\
Osteoarthritis & $18(30)$ \\
Poor Vision & $14(23.3)$ \\
Cardiac Related & $12(20)$ \\
Chronic Obstructed Pulmonary Disease & $10(16.7)$ \\
Pain & $8(13.3)$ \\
Cerebrovascular Accident & $7(11.7)$ \\
Hypothyroidism & $6(10)$ \\
Dementia & $5(8.3)$ \\
Hard of Hearing & $4(6.7)$ \\
Cancer & $3(5)$ \\
Depression & $2(3.3)$ \\
Falls & $2(3.3)$ \\
Psychiatric & $2(3.3)$ \\
Other & $33(55)$ \\
\hline
\end{tabular}

Note. Other is a compilation of rarely occurring medical conditions among all subjects such as leg cramps, seasonal allergies, gout, urinary incontinence, blood clots, vertigo and facial paralysis secondary to surgery as a child; Percents do not add up to 100 because subjects had multiple medical conditions.

\subsection{Executive function and cognitive assessment measures}

Table 3 provides the descriptive results of the different EF measures as well as the MMSE for the sample of elders with SN.

Descriptive analyses revealed elders with SN in this sample scored in the normal range on the MMSE, CLOX II Drawing Test, Trails A and B and the EXIT 25 interview. In contrast, they were more likely to have scores consistent with executive deficits on the CLOX I and D-KEFS card sort tests.

As can be seen in Table 4, while 85\% of subjects scored in the normal range for the EXIT 25, the majority of subjects (58.3\% to 86.1\%) showed deficits on the D-KEFS card sort test conditions. For example, when asked to sort the cards in as many unique ways as possible in Condition 1, the examinee would sort the first few sets correctly but then would repeatedly generate incorrect sorts or would state he/she could not think of any new sorts. This same type of card sort recognition problem occurred in condition 2 when the examinee was asked to identify the pattern sorted by the assessor. In both conditions, the examinee was unable to do many of the eight pre-determined correct sorts (i.e. as per the D-KEFS' instructions, there are 8 card sorts the examinee are asked to identify) or could not identify many of the eight correct sorts when provided by the administrator. Thus, elders with SN in this study exhibited difficulties in tasks that required generating new concepts, inhibiting previous conceptual thoughts, or initiating novel ideas. Furthermore, these low scores are indicative of perseverative tendencies since they would repeat a card sort description whether correct or incorrect, thus demonstrating that they were unable to inhibit prior thoughts or ideas. The MMSE was not included in this table since it is not an EF measure. 
Table 3. Results of EF and global cognition measures for community-dwelling elders with Adult Protective Services validated self-neglect in this study

\begin{tabular}{|c|c|c|c|c|c|}
\hline Measure & $\mathbf{N}$ & Mean \pm SD & Median & Mode & Range \\
\hline MMSE & 48 & $26.10 \pm 3.033$ & 27 & 29 & $19-30$ \\
\hline CLOX I & 46 & $10.46 \pm 3.982$ & 12 & 13 & $2-15$ \\
\hline CLOX II & 44 & $13.20 \pm 2.216$ & 13.50 & 15 & $5-15$ \\
\hline EXIT 25 & 46 & $8.63 \pm 6.005$ & 8 & 10 & $1-25$ \\
\hline TMT A $^{*}$ & 42 & $74.95 \pm 48.708$ & 68.50 & 22 & $22-223$ \\
\hline TMT B ${ }^{*}$ & 39 & $145.67 \pm 64.152$ & 140 & 83 & 64-342 \\
\hline $\begin{array}{l}\text { D-KEFS confirmed correct } \\
\text { sorts (Condition } 1)^{\#}\end{array}$ & 36 & $8.58 \pm 3.573$ & 9.50 & 11 & $2-14$ \\
\hline $\begin{array}{l}\text { D-KEFS free sort } \\
\text { description score (Condition } \\
1)^{\#}\end{array}$ & 36 & $8.75 \pm 3.549$ & 10.00 & 11 & $1-15$ \\
\hline $\begin{array}{l}\text { D-KEFS recognition } \\
\text { description score (Condition } \\
2)^{\#}\end{array}$ & 37 & $8.36+3.474$ & 8 & 12 & $2-15$ \\
\hline $\begin{array}{l}\text { D-KEFS combined } \\
\text { description score }\end{array}$ & 36 & $8.56 \pm 3.676$ & 9 & 11 & $1-16$ \\
\hline $\begin{array}{l}\text { D-KEFS combined incorrect } \\
\text { descriptions }{ }^{\#}\end{array}$ & 36 & $6.39 \pm 4.865$ & 6.5 & 1 & $1-16$ \\
\hline $\begin{array}{l}\text { D-KEFS combined } \\
\text { No/Don't Know responses" }\end{array}$ & 36 & $6.67 \pm 5.601$ & 6 & 1 & $1-16$ \\
\hline Percent Sorting Accuracy ${ }^{\#}$ & 36 & $6.83 \pm 3.653$ & 7.50 & 9 & $1-13$ \\
\hline $\begin{array}{l}\text { Percent Description } \\
\text { Accuracy }{ }^{\#}\end{array}$ & 36 & $7.72 \pm 3.494$ & 8 & 8 & $1-14$ \\
\hline
\end{tabular}

Note. $*=$ Time in seconds, ${ }^{\#}$ Converted to scaled scores based on age

Descriptive analyses revealed elders with SN in this sample scored in the normal range on the MMSE, CLOX II Drawing Test, Trails A and B and the EXIT 25 interview. In contrast, they were more likely to have scores consistent with executive deficits on the CLOX I and D-KEFS card sort tests.

\subsection{Associations among the EF measures and demographics}

The associations between age and level of education and each of the EF measures (MMSE, CLOX Drawing Test, D-KEFS Card Sort Test, Trails A \& B, and EXIT 25) were assessed using Pearson product-moment correlation coefficient. According to Cohen (1988), the following ranges were used to detect the effect size: $r=.10$ to .29 (small), $r=.30$ to .49 (medium), and $r=.50$ to 1.0 (large) ${ }^{[34]}$.

As can be seen in Table 5, only small to moderate sized correlations were detected. Moderate sized statistically negative correlations were detected between age and CLOX II and D-KEFS-CIDC 1 \& 2 indicating as age increases, performance on these two measures becomes poorer. Statistically significant positive correlations were detected between age and D-KEFS CN/DK and TMT A. Thus, as age increased, scores increased indicating poorer performance. Therefore, in this study age was associated with performance; older subjects did not perform as well on the CLOX II, TMT A and parts of the D-KEFS' tests as younger subjects. The MMSE and CLOX II were positively correlated with education indicating an association between education levels and performance. Similarly, performance on the TMT B and EXIT 25 were negatively correlated with education level .Therefore, in this study education was associated with performance; subjects with higher education demonstrated better performance on the MMSE, CLOX II, TMT B and EXIT 25 measures, than subjects with lower educational levels. Only results with moderate correlations and their significant levels are presented in Table 5. 
A one-way between group analysis of variance was conducted to determine the impact of race on the performance for each of the dependent measures. There was a statistically significant difference at the $p<.05$ level in MMSE scores [F $(3,44)=$ 6.06, $p=.002]$ and EXIT scores $[\mathrm{F}(3,42)=4.14, p=.012]$ for the different racial groups among each of the dependent measures. However, because of the small number of subjects in the Asian category, we could not determine where the differences among the races occurred.

Table 4. Cut-off scores for Executive Dysfunction (ED) for each of the Executive Function (EF) measures and number of community-dwelling elders with Adult Protective Services validated self-neglect in this study who met the criteria consistent for ED

\begin{tabular}{|c|c|c|c|c|}
\hline Measure & $\mathbf{N}$ & $\begin{array}{l}\text { Cut-Off Scores } \\
\text { for ED }\end{array}$ & $\begin{array}{l}\text { Number (\%) } \\
\text { Meeting Criteria } \\
\text { for ED }\end{array}$ & EF Subset Assessed \\
\hline CLOX I & 46 & $<12$ & $18(39)$ & \multirow{2}{*}{ Inhibition, Spatial Working Memory } \\
\hline CLOX II & 44 & $<10$ & $10(22.7)$ & \\
\hline EXIT 25 & 46 & $>15$ & $7(15.2)$ & $\begin{array}{l}\text { Concept Generation, Inhibition, } \\
\text { Spatial and Verbal Working Memory }\end{array}$ \\
\hline TMT A & 42 & > 78 seconds & $13(30.9)$ & \multirow[t]{2}{*}{ Inhibition, Spatial Working Memory } \\
\hline TMT B & 39 & $>273$ seconds & $2(5.1)$ & \\
\hline $\begin{array}{l}\text { D-KEFS confirmed correct sorts } \\
\text { (Condition 1) }\end{array}$ & 36 & $<10 \pm 3^{*}$ & 21(58.3) & $\begin{array}{l}\text { Concept } \\
\text { Generation }\end{array}$ \\
\hline $\begin{array}{l}\text { D-KEFS free sort description score } \\
\text { (Condition 1) }\end{array}$ & 36 & $<10 \pm 3^{*}$ & 21(58.3) & Concept Generation, Inhibition \\
\hline $\begin{array}{l}\text { D-KEFS Sort recognition score } \\
\text { (Condition 2) }\end{array}$ & 37 & $<10 \pm 3^{*}$ & $23(62.2)$ & Concept Generation, Inhibition \\
\hline $\begin{array}{l}\text { D-KEFS combined description } \\
\text { score }\end{array}$ & 36 & $<10 \pm 3^{*}$ & $22(61.1)$ & Concept Generation, Inhibition \\
\hline $\begin{array}{l}\text { D-KEFS combined incorrect } \\
\text { descriptions }\end{array}$ & 36 & $<10 \pm 3^{*}$ & $25(69.4)$ & Concept Generation \\
\hline D-KEFS combined No/Don’t & 36 & $<10 \pm 3^{*}$ & 23 (63.9) & Concept Generation \\
\hline Know responses & & & & \\
\hline Percent Sorting Accuracy & 36 & $<10 \pm 3^{*}$ & $31(86.1)$ & Concept Generation \\
\hline Percent Description Accuracy ${ }^{\#}$ & 36 & $<10 \pm 3^{*}$ & $28(77.8)$ & Concept Generation \\
\hline
\end{tabular}

Note. *Scaled score is $\mathrm{X}+\mathrm{SD} ;{ }^{*}$ Converted to scaled scores based on age

\section{Discussion}

This is the first study to comprehensively investigate EF in older adults with SN utilizing four measures of EF. Theory suggests that ED may be an important component in older adults with SN. Prior studies have used the MMSE and the 
Clock Drawing Test to assess cognitive function in this population. However, neither of these measures adequately assesses the dimensions of EF, and thus do not provide definitive insights into the executive capabilities of elders with SN. Recently, Dong \& colleagues demonstrated that a decline in EF was associated with confirmed elders with SN in a prospective population-based study utilizing the symbol digit modalities test, a measure of processing speed ${ }^{\text {[35] }}$. Results from the current study provide additional support for the theory that elders with SN exhibit impairments in ED. Specifically, disruptions in the EF dimensions of “concept generation”, "planning”, “inhibition”, and "spatial working memory" were identified from the low scores on the CLOX I Drawing Test and the D-KEFS Card Sort Test. It also provides evidence that an EF battery of tests can be administered to this population in their homes based on the number of subjects who were willing to complete these measures as previously reported.

Table 5. Pearson-product moment correlations between age, educational level, executive function and global cognitive measures

\begin{tabular}{|c|c|c|c|}
\hline \multirow{2}{*}{ Measure } & \multirow{2}{*}{$\begin{array}{l}\text { Number of subjects who } \\
\text { completed each measure }\end{array}$} & Age & Educational Level \\
\hline & & $r(p)^{*}$ & $r(p)^{*}$ \\
\hline MMSE & 48 & - & $r=.364(p=.011)$ \\
\hline CLOX II & 44 & $r=-.327(p=.030)$ & $r=.311(p=.040)$ \\
\hline DKEFS-CIDC1\&2 & 36 & $r=-.402(p=.015)$ & - \\
\hline DKEFS-CN/DK & 36 & $r=.364(p=.029)$ & - \\
\hline TMT A & 42 & $r=.454(p=.003)$ & - \\
\hline TMT B & 39 & - & $r=-.317(p=.049)$ \\
\hline EXIT 25 & 46 & - & $r=-.344(p=.019)$ \\
\hline
\end{tabular}

Note. DKEFS: CIDC1\&2 = Combined Incorrect Descriptions Conditions 1 \& 2, CN/DKR = Combined No/Don’t Know Responses; * $p<.01(2$-tailed)

Consistent with the ED literature, this study found that individuals with high MMSE scores may test positive for scores consistent $\mathrm{ED}^{[12]}$. As previously mentioned, the MMSE is a global screen for cognition (i.e. dementia) and therefore, does not always identify individuals with impaired EF or frontal lobe pathology. The instruments that made up the EF battery for this study were chosen because they measured different dimensions of EF. An interesting finding is that the majority of subjects scored in the normal range for the EXIT 25, a tool designed to measure 4 of the 5 EF dimensions. However, on average, subjects showed deficits on the CLOX I and the D-KEFS Card Sort Test. Perhaps the EXIT 25 is not sensitive to identifying ED in elders with SN in the community settings, whereas the CLOX I and D-KEFS Card Sort Test may be more definitive in assessing ED in elders with SN.

An important component in assessing executive capacity is an individual's ability to articulate and then demonstrate their decision-making ability ${ }^{[36,37]}$. Being able to demonstrate a decision involves initiating appropriate actions necessary to follow through with the decision. For example, if an individual is diagnosed with hypertension, he/she needs to be aware of the disease process, know when and how to obtain and self-administer medications, implement other life style changes (i.e. low sodium diet, exercise), and be aware of the consequences of not managing their disease (i.e. cerebrovascular accident, myocardial infarction). The inability to plan, form concepts and inhibit behaviors is often seen in elders with SN. This concept is further supported by the low scores for the D-KEFS card sort test (58\%-86\%) and the CLOX I (39\%), more direct measures of executive function.

In contrast to having low scores on the D-KEFS and CLOX I, the majority of subjects scored in the normal range for the MMSE, TMT A and CLOX II which typically correlate with global cognition. The MMSE is often a measure used in the comprehensive geriatric assessment, however, it is not designed to screen for ED. Therefore, individuals who pass this test may not receive further screening for ED which could possibly put them at risk for further decline if other medical 
conditions are present. Thus, more direct measures of EF need to be included in geriatric assessments, particularly with elders who are suspected of SN.

The D-KEFS card sort test has several sub-scores. On average, subjects had scores consistent with executive deficits on every portion of the test. The majority of subjects responded "no" or "I don't know" for both card sorts indicating either a neurostructural (i.e. bifrontal cortical and subcortical damage) or non-neurostructural (i.e. depression, lack of interest) condition may be present. According to Delis, et al, neurostructural damage causes individuals to not be able to form concepts as well as the inability to initiate the problem solving process ${ }^{[30]}$. Overall, having scores consistent with executive deficits on the D-KEFS indicates weak executive function skills in areas commonly seen in elders with SN: lack of initiation (e.g. inability to start a task like taking a bath), problem solving behaviors (e.g. unable to identify the steps to have the car fixed), concept formation skills (e.g. inability to generate a new idea about how to organize possessions) and flexibility of thinking (e.g. inability to switch from one idea to a novel idea like turning off the stove when through with cooking).

Moreover, the D-KEFS card sort test is the only measure that includes the EF dimension of "planning" which may explain the inability of elders with SN to initiate and demonstrate an articulated decision. The majority of subjects provided very few correct card sort descriptions, meaning they were unable to describe how the cards were correctly sorted and repeatedly stated the incorrect descriptions. Delis, Kaplan \& Kramer suggest this incorrect pattern of responses often reflects perseverative tendencies in addition to poor concept formation abilities ${ }^{[30]}$. For instance, elders with self-neglect may be aware of their multiple, untreated medical conditions yet refuse to see a clinician even in life-threatening situations.

Although executive tests have been previously been used with elders with $S N^{[17,35,38]}$, this is the first study to utilize four EF measures and to assess the different EF dimensions in older adults with SN. The EF battery used in this study takes about an hour to administer which may discourage busy clinicians in both in-patient and out-patient settings. However, self-report of individual SN is unlikely and probably unreliable. Since the CLOX Drawing Test and TMT A \& B measure the same EF dimensions perhaps they could be eliminated from the EF battery to reduce administration time. While the MMSE is useful for measuring mental status, it is not a useful tool to measure ED. In this study, 39 of the 48 subjects who completed the MMSE had scores of 24 or higher. It was somewhat surprising that subjects in this study had been seen by their primary care physicians within 3 months of participation in this study, yet, they continued to live in a state of neglect. Knowing an elder suffers from ED may change the health care provider's plan of care and improve the individual's quality of life. It is imperative to rule out reversible causes of ED once this condition has been identified. For example, if ED is caused by depression, treating the depression may reverse the ED and perhaps resolve SN. In contrast, if there are no reversible causes of $\mathrm{ED}$, it is prudent to devise a treatment plan that allows a safe and monitored environment to prevent further decline.

Individuals with SN are often difficult to engage in research. In this study we were able to enroll $62.5 \%$ of the eligible referrals, but some refused to complete all of the tests. In addition, performance on some of the measures may have been affected by fatigue and thus the subjects may have not done as well as they would have if fewer tests were administered. Furthermore, the sample was identified as individuals with SN by APS workers who do not have the benefit of ED measures to help them make that determination so some of those identified with $\mathrm{SN}$, may have been improperly identified.

\section{Conclusions}

Prior research has generally relied on only one or two EF measures to assess individuals with SN. This study demonstrates an EF battery can be administered in the community setting to older adults with APS substantiated SN. If mental status assessment is the only measure used to determine EF, ED is likely to be missed in individuals with intact global cognition, thus delaying necessary treatment. Incorporating an EF battery into a comprehensive geriatric assessment will increase the 
clinician's likelihood of identifying individuals with $\mathrm{SN}$, and thus, the initiation of a multidisciplinary treatment plan targeted at multiple dimensions of ED. Future studies should attempt to determine the different etiologies of ED, as well as testing interventions that may prevent or reverse SN from progressing to further deterioration and even death. Although this study was conducted in the United States, larger sample sizes across international countries are needed to further investigate how different cultural and racial groups perform on these measures.

\section{References}

[1] Administration on Aging. The 2004 Survey of State Adult Protective Services: Abuse of Adults 60 Years of Age and Older[Internet]. 2006. Available from: http://www.aoa.gov/NCEAroot/Main_Site/pdf/2-14-06\%20FINAL\%2060+REPORT.pdf

[2] National Center on Elder Abuse. Abuse of adults aged 60+ 2004 survey of adult protective services[Internet]. 2006. Available From: http://www.ncea.aoa.gov/ncearoot/Main_Site/Library/Statistics_Research/Abuse_Statistics/National_Statistics.aspx

[3] Phua DH, Ng TW, Seow E. Epidemiology of suspected elderly mistreatment in Singapore. Singapore Medical Journal. 2008; 49(10): 765-773.

[4] McDermott S. The devil is in the details: self-neglect in Australia. Journal of Elder Abuse and Neglect. 2008; 20(3): $231-250$. PMid:18928052 http://dx.doi.org/10.1080/08946560801973077

[5] Lee SM, LoGiudice D. Phenomenology of squalor, hoarding and self-neglect: an Australian aged care perspective. Internal Medicine Journal. 2012: 98-101. PMid:22276561 http://dx.doi.org/10.1111/j.1445-5994.2011.02634.x

[6] Lauder W, Roxburgh M. Self-neglect consultation rates and comorbidities in primary care. International Journal of Nursing Practice. 2012; 18(5): 454-461. PMid:23009374 http://dx.doi.org/10.1111/j.1440-172X.2012.02065.x

[7] Day MR, Leahy-Warren P. Self-neglect. 2: nursing assessment and management. Nursing Times. 2008; 104(25): $28-29$. PMid:18672840

[8] Day MR, Bantry-White E, Glavin P. Protection of vulnerable adults: an interdisciplinary workshop. Community Practice. 2010; 83(9): 29-32. PMid:20879664

[9] Alexa ID, Ilie AC, Alexandroaia B, Costin G, Emmanouil-Stamos P, Raiha I. Self-neglect in the case of the elderly. Where are we now? Revista Medico-Chirurgicala a Societatii de Medici si Naturalisti din Lasi. 2011; 115(2): 337-340.

[10] Sauvageau A, Hunter BC. Self-neglect: adaptation of a clinical tool to the practice of the medical examiner. American Journal of Forensic Medicine Pathology. 2012; 33(3): 289-292. PMid:20938322 http://dx.doi.org/10.1097/PAF.0b013e3181f70d7c

[11] Workman RH, McCullough LB, Molinari V, Kunik ME, Orengo C, Khalso DK, Rezabek P. Clinical and ethical implications of impaired executive control functions for patient autonomy. Psychiatric Services. 2000; 51: 359-363. PMid:10686244 http://dx.doi.org/10.1176/appi.ps.51.3.359

[12] Royall DR, Palmer R, Chiodo LK, Polk MJ. Declining executive control in normal aging predicts change in functional status: The freedom house study. Journal of the American Geriatrics Society. 2004; 52(3): 346-352. PMid:14962147 http://dx.doi.org/10.1111/j.1532-5415.2004.52104.x

[13] Royall DR, Palmer R, Chiodo LK, Polk MJ. Executive control mediates memory's association with change in instrumental activities of daily living: The freedom house study. Journal of the American Geriatrics Society. 2005; 53(1): 11-17. PMid:15667370 http://dx.doi.org/10.1111/j.1532-5415.2005.53004.x

[14] Dyer CB, Pickens S, Burnett J. Vulnerable elders when it is no longer safe to live alone. Journal of the American Medical Association. 2007; 298(12): 1448-1450. PMid:17895463 http://dx.doi.org/10.1001/jama.298.12.1448

[15] Folstein MF, Folstein SE, McHugh PR. Mini-mental state: A practical method for grading cognitive state of patients for the clinician. Journal of Psychiatric Research. 1975; 12: 189-198. http://dx.doi.org/10.1016/0022-3956(75)90026-6

[16] Royall DR, Lauterbach EC, Cummings JL, Reeve A, Rummans TA, Kaufer DI,et al. Executive control function: A review of its promise and challenges for clinical research. Journal of Neuropsychiatry and Clinical Neurosciences. 2002; 14(4): $377-405$. PMid:12426407 http://dx.doi.org/10.1176/appi.neuropsych.14.4.377

[17] Dyer CB, Goodwin JS, Pickens-Pace S, Burnett J, Kelly PA. Self-Neglect among the elderly: A model based on more than 500 patients seen by a geriatric medicine team. The American Journal of Public Health. 2007; 97(9): 1671-1676. PMid:17666694 http://dx.doi.org/10.2105/AJPH.2006.097113

[18] Schillerstrom JE, Horton MS, Royall DR. The impact of medical illness on executive function. Psychosomatics, 2005; 46(6): 508-516. PMid:16288129 http://dx.doi.org/10.1176/appi.psy.46.6.508

[19] National Center on Elder Abuse. National elder abuse incidence study[Internet]. 1998. Available from: http://www.aoa.gov/eldfam/Elder_Rights/Elder_Abuse/AbuseReport_Full.pdf. 
[20] Dyer CB, Pavlik VN, Murphy KP, Hyman DJ. The high prevalence of depression and dementia in elder abuse or neglect. Journal of the American Geriatrics Society. 2000; 48: 205-208. PMid:10682951

[21] Burnett J, Coverdale JH, Pickens S, Dyer CB. What is the association between self-neglect, depressive symptoms and untreated medical conditions? Journal of Elder Abuse \& Neglect. 2006; 18(4): 25-34. PMid:17972657 http://dx.doi.org/10.1300/J084v18n04_04

[22] Pickens S, Burnett J, Naik AD, Holmes HM, Dyer CB. Is pain a significant factor in elder self-neglect? Journal of Elder Abuse \& Neglect. 2006; 18(4): 51-61. PMid:17972659 http://dx.doi.org/10.1300/J084v18n04_06

[23] Pickens S, Naik AD, Burnett J, Kelly PA, Gleason M, Dyer CB. The utility of the Kohlman evaluation of living skills test is associated with substantiated cases of elder self-neglect. Journal of the American Academy of Nurse Practitioners. 2007; 19: 137-142. PMid:17341281 http://dx.doi.org/10.1111/j.1745-7599.2007.00205.x

[24] Dick C. Self-Neglect: Diogenes syndrome and dementia. The Kansas Nurse. 2006; 81(9): 12-13. PMid:17111646

[25] Dong X, Simon MA, Mendes de Leon C, Fulmer T, Beck T, Hebert L, et al. Elder self-neglect and abuse and mortality risk in a community-dwelling population. Journal of the American Medical Association. 2009; 302(5): 517-526. PMid:19654386 http://dx.doi.org/10.1001/jama.2009.1109

[26] Dick JP, Guiloff RJ, Stewart A, Blackstock J, Bielawska C, Paul EA, Marsden CD. Mini-mental state examination in neurological patients. Journal of Neurology, Neurosurgery, and Psychiatry. 1984; 47(5): 496-499. http://dx.doi.org/10.1136/jnnp.47.5.496

[27] Strauss E, Sherman EMS, Spreen O. A Compendium of Neuropsychological Tests: Administration, Norms, and Commentary (3rd ed.). New York, NY: Oxford University Press; 2006.

[28] Reitan RM. Validity of the trails making test as an indicator of organic brain damage. Perceptual and Motor Skills. 1958; 8: 271-276.

[29] Royall DR, Mahurin RK, Gray KF. Bedside assessment of executive cognitive impairment: The executive interview. Journal of the American Geriatrics Society. 1992; 40: 1221-1226. PMid:1447438

[30] Delis DC, Kaplan E, Kramer JH. Delis-Kaplan Executive Function System Examiner’s Manual. San Antonio, TX: Pearson; 2001.

[31] Delis DC, Squire LR, Bihrle A, Massman P. Componential analysis of problem-solving ability: Performance of patients with frontal lobe damage and amnesic patients on a new sorting test. Neuropsychologia. 1992; 30(8): 683-697. http://dx.doi.org/10.1016/0028-3932(92)90039-O

[32] Royall DR, Cordes JA, Polk M. CLOX: An executive clock drawing task. Journal of Neurology, Neurosurgury, and Psychiatry. 1998; 64: 588-594. http://dx.doi.org/10.1136/jnnp.64.5.588

[33] IBM SPSS Inc. IBM SPSS Graduate Pack Version 19.0 for Windows User’s Guide. IBM Inc., Armonk, NY; 2011.

[34] Cohen JW. Statistical power analysis for the behavioral sciences (2nd ed.). Hillsdale, NJ: Lawrence Erlbaum Associates; 1988.

[35] Dong S, Simon MA, Wilson RS, Mendes De Leon C, Rajan KB, Evans DA. Decline in cognitive function and risk of elder self-neglect: finding from the Chicago health aging project. Journal of the American Geriatric Society. 2010 ; 58 (10): $2292-2299$. PMid:21143438 http://dx.doi.org/10.1111/j.1532-5415.2010.03156.x

[36] Naik AD, Teal CR, Pavlik VN, Dyer CB, McCullough LB. Conceptual challenges and practical approaches to screening for capacity for self-care and protection in vulnerable older adults. Journal of the American Geriatrics Society. 2008; 56: S266-S270. PMid:19016970 http://dx.doi.org/10.1111/j.1532-5415.2008.01979.x

[37] Naik AD, Lai JM, Kunik ME, Dyer CB. Assessing capacity in suspected cases of self-neglect. Geriatrics. 2008 ; 63(2): $24-31$. PMid:18312020

[38] Schillerstrom JE, Salazar R, Regwan H, Bonugli RJ, Royall DR. Executive function in self-neglecting adult protective services referrals compared with elder psychiatric outpatients. American Journal of Geriatric Psychiatry. 2009; 17(10): 907-910. PMid:19910879 http://dx.doi.org/10.1097/JGP.0b013e3181b4bf64 